\title{
La justa compensación en los casos de expropiación
}

\author{
por el Honorable LOFTUS E. BECKER, \\ Consejero Legal del Departamento de Estado \\ de los Estados Unidos de Norte-América.
}

Todos estamos de acuerdo en que la regla del derecho debe regir las relaciones entre los Estados. Todos conocemos las consecuencias que derivan de otros procedimientos, que se han manifestado en el curso de dos guerras mundiales en menos de cincuenta años; consecuencias que fueron suficientemente aterradoras entonces, pero que, ahora, en una edad nuclear, se han de contemplar con horror.

Esta Asociación está dedicada a promover y a reforzar la regla del derecho en el campo de los asuntos internacionales. Este es su declarado propósito, su verdadera razón de ser. Es por esto que nos hemos reunido durante los últimos días; es por esto que nos hallamos reunidos esta noche. Como hombres prácticos, sabemos que esta tarea en la cual estamos comprometidos no constituye algo que se puede hacer en forma caprichosa y mediante estremecimientos. Se trata de una labor continuada. Debe pro* cederse con constancic. De otra manera, mucho de lo que se logre puede perderse; mucho de lo que se ha conseguido durante los últimos años podrá pronto perderse por falta de atención.

Por naturaleza y por tradición tendemos a ser gente optimista. Para nosotros la idea del progreso, de un adelanto firme hacia una meta conocida, constituye una segunda naturaleza. Por consiguiente, la idea de un retroceso nos repugna. Sin embargo, reveses ocurren aquí en el campo que hemos escogido, así como ocurren en otros campos del estuerzo humano. Así como algunos pueden resultar de nuestros propios

MOTK: Traducido de "Proceedings of the Amexican Society of International Law at its Fifty" Third Annual Meeting, held at Washington-April 30-MaY. 2, 1959" pp. 336-344), par el Dr. Javier Kiefer-Marchand.

Agradocemos a la Sociedad Americana de Derecho Internacional, que gentilmente. nos ha autorizado a publicar esta traducción del inglés. 
errores en su mayoría son causados por acontecimientos muy ajenos a nuestro poder de control. Pero, cualesquiera que sean las causas, siempro que un principio vital del derecho internacional es violado o desconocido. nuestro deber es claro. Debemos hacer cuanto podamos para reparar la violación, para restablecer y revitalizar el principio que ha sido dañado.

Pero, no es mi intención hablar de generalidades esta noche. En cambio, deseo examinar con ustedes un ejemplo específico de como algo que alguna vez tue un firme principio de derecho internacional, ha sido viciado en los últimos años y como el lento, el penoso proceso de restablecerlo en su primitiva fuerza está logrando éxito. Este ejemplo, estoy seguro, es de interés para todos nosotros. Se ha tomado del campo vital de la protección a la propiedad. Es, y creo que todos estamos de acuerdo con esto, el principio básico de la ley internacional según el cual la propiedad de los extranjeros no puede ser tomada por el Estado sin el pago de una justa compensación. Más aún, este principio constituye la piedra angular de toda estructura que se refiere a la protección de la propiedad, y sin ella el desarrollo económico, tan ardientemente deseado en todas partes del mundo, se logrará muy lentamente.

Antes de la primera Guerra Mundial, existían pocas dudas sobre la validez de este principio. En general, los gobiernos y los pueblos lo aceptaban y lo consideraban como incrustado en la costumbre del derecho internacional. Sus bases en consideraciones de razón, equidad y justicia exan tan obvias que la aceptación general del principio era virtualmente tócita en su carácler. Que este principio era parte válida de la ley internacional era algo tan sencillo que no era menester mencionarlo.

Lo primera violación importante de esta regla vital se produjo al final de la guerra. En 1917, el Gobiemo Soviético abolió la propiedad privada de la tierra. En los años siguientes, nacionalizó los bancos, las minas y las industrias en general. En todos los casos los términos eran los mismos: ninguna compensación a los propietarios, ya fueran rusos o extranjeros. Las expropiaciones del Soviet no fueron sinó las primeras de una espantosa sucesión de tales secuestros en el período comprendido entre las dos querras, justificados distintamente por razones de teoría política, necesidad económica o reforma social.

Socialmente con el fin de recordar hasta qué punto se efectuó este proceso de nacionalización sin completa compensación déjenme cirar algunos ejemplos. No menos de cinco países de la Europa Oriental expropiaron tierras en el desarrollo de sus programas de reforma agraria. La Alemania Nazi confiscó la propiedad de los Judios donde se hallaba y absorbió sistemáticamente las propiedades privadas en los territorios que ocupaba. Méjico expropió las propiedades petroleras, granjas y tierras de cultivo. Como todos lo sabemos, la Segunda Guerra Mundial aceleró este procedimiento que sigue aún. Poca necesidad hay de recordarlo. Los nombres y los casos se hallan presentes en nuestra memoria: los satélites, la Cía. Petrolera AngloIrania, el Canal de Suéz, y recientemente, Indonesia que se ha apoderado de la mayoría de las propiedades perteneciendo a holandeses, aún sin título para ello, con una provisión perra compensación, pero sin que se hubiera dado los pasos necesarios para hacerla efectiva. 
Al mencionar esta relación de los hechos, no pretendo necesariamente condenar la nacionalzación como tal. No debe existir ningún equívoco sobre este punto; que me sea permitido repetir lo que ya dije, semanas atrás, en la "Inter-American Bar Association". No discuto el derecho de ningún país de expropiar la propiedad privada con fines de utilidad pública, mediante el pago de una justa compensación. El derecho de un país para hacer esto, no se halla, y nunca estuvo, en discusión. De lo que estoy hablando es del esfuerzo que han hecho algunos, incluyendo lamentablemente a algunos abogados internacionales, para establecer principios legales que puedan justificar y permitir la expropiación de la propiedad privada sin justa compensación.

Tal es la significación de los actos que acabo de mencionar. No solamente han constituído un desmedro en la práctica de los Estados; han constituído, además, un atentado al principio legal afectado. Los Estados se han apoderado de la propiedad extranjera sin compensación; o han ofrecido solamente una compensación parcial; o han ofrecido justa compensación. pero por un motivo u otro han logrado evadir esa responsabildad. En un caso, una promesa de indemnización total se redujo, mediante numerosas manipulaciones financieras y devaluaciones, $\alpha$ un pago actual que representa el uno por ciento del valor real de la propiedad expropiada.

Los Estados han presentado una serie de justificaciones para apoderarse de la propiedad extranjera sin justa compensación. Mencionan la prevalencia de la importancia social de los fines con los cuales se apoderan de Ia propiedad. Indican su incapacidad de pagar. Dicen que el trato del extranjero no debe ser mejor que el del nacional, $y$ que ese trato es justo. Establecen una discusión entre las expropiaciones individuales y las que tienen un carǵcter general e impersonal, insistiendo en que una compensación parcial es justa y legal para las últimas. Significativamente, pero sin que esto fuera de extrañar, niegan que una compensación constituya una regla válida del derecho internacional, por lo menos en cuanto se refiere a programas generales de nacionalización. En cambio, tratan de cubrir los conceptos de compensación parcial con la dignidad y la fuerza del derecho internacional.

Estos reclamos no constituyen ninguna novedad, ni son tampoco un producto exclusivo de este período reciente de la post-guerra. La Unión Soviética negó siempre toda obligación, bajo las reglas de la ley internacional o de otra manera, para abonar cualquier compensación por las propiedades expropiadas durante las nacionalizaciones de 1917, cuando más tarde aceptó, por razones de conveniencia, algunos tratos sobre este punto.

Nuevamente, en 1929, una discusión sobre las reglas de una justa compensación en la ley internacional, en la Conferencia de París sobre el Trato de los Extranjeros, evocó una discusión entre los defensores de la regla de la justa compensación y los Estados que insisten en que no hay reglas de derecho internacional que se refieran a expropiaciones de carácter general y que lo más que un estado pueda hacer era conceder un trato igual al que otorga $\alpha$ los nacionales. Propuestas referentes al principio de compensación "equitativa" fueron aprobadas por grandes mayorias. 
Otra vez, en la controversia entre los Estados Unidos y Méjico, en 1938, el gobiemo de esie último país declaró que:

"no existe, en la ley internacional, ningún principio univer. " salmente aceptado por los países, ni por los autores de " tratados sobre la materia, que haría obligatorio el pago "de una compensación adecuada por expropiaciones de " carácter general e impersonal" (1).

En el reciente período de la post guerra, los estados han hecho algo más que discutir sobre estas afirmaciones como base para defender las compensaciones parciales, o ninguna compensación. La práctica de los estados, sin embargo lamentable, es fácil de comprender cuando las presiones -política, económica, social, ideológica- que se ejercen sobre el gobierno, especialmente en tiempos de guerra o de depresión o de revolución social, se tomen en cuenta.

Lo que se comprende menos, y que es tanto más lamentable, es la facilidad con la que algunos publicistas, escritores y profesores de derecho internacional, han prestado su prestigio y cnoyo al concepto de la compensación parcial. De hecho, una teoría bastante coherente y realística se ha construído, principalmente, pero no totalmente, desde el final de la Segunda Guerra Mundial, para cpoyar la compensación parcial. Esta doctrina se ha resumido en los siguientes términos:

"Autores de Derecho Internacional que sostienen la teoría según la cual en ciertas circunstancias el pago de una mera compensación parcial es admisible, distinguen las expropiaciones de carácter general y las llamadas expropia. ciones individuales".

"En el primer grupo... clasifican todas las expropia. ciones levacias a cabo con relación a una modificación de la estructura económica o social de un Estado determinado, $\mathrm{y}$ opinan que en estos casos el Estado cumple sus obligaciones en clianto al pago de compensaciones, mediante el pago de tal compensación que sea razonable en esas circunstancias. Consideran que la ley internacional no puede oponerse al desarrollo de formas sociales imponiendo una obligación de pagar una compensación hasta un punto fuera de proporción con los recursos financieros del Estado nacionalizador". (2).

El más ligero examen de esta noción indica que la misma manera de razonar puede emplearse igualmente para defender la teoría de que no

(1) 5 Foreign Relations (1938) 680 .

(2) International Law Association, "The Legal Effects of Nationalizations Enacted by Foreign: States", Netherlands Branch Committee Report 24 (1958). 
existe ninguna obligación bajo la ley internacional de pagar compensación alguna.

Por esta razón., resulta particularmente enojoso que tantos abogados internacionales de países cuyos gobiernos sostienen el principio de la justa compensación, hayan tratado de justificar o condenar la compensación parcial. En el período de la post-guerra, el publicista francés, Friedman, fué lejos en la defensa de la compensación parcial sobre terrenos pragmáticos, basada en la práctica de los Estados, a la que considera la única fuente del derecho internacional. El punto nuclear de su posición, sin embargo, parece denegar toda obligación para respetar los derechos adquiridos, particularmente en cuanto se refieren a los derechos adquiridos en oposición a las disposiciones de una ley posterior. Niega simplemente tal obligación como teoría desacreditada, basada en cambio sobre la idea de la inmutabilidad de la ley objetiva, que nadie puede seriamente sostener (3). Algunas posiciones menos extremas en favor de la idea de la compensación parcial, cuando la expropiación es de carácter general, han sido expresadas por otros publicistas franceses, por el autor suizo R. Bindschedler, $y$ aún por algunos escritores americanos.

Un fuerte apoyo a la teoría de la compensación parcial fué adelantado por el profesor trancés, Albert de la Pradelle, en un proyecto preparado en 1951 para su estudio por el Instituto de Derecho Internacional. Significativamente, sin embargo, este proyecto fué agudamente criticado por el profesor holandés, Jan Verzijl, quien declaró que se negaba a aceptar las tendencias según las cuales los estados pueden enriquecerse a expensas de los extranjeros como una regla que merezca ser sancionada por el derecho internacional. En la reunión del Instituto, en Siena, 1952, se produjo tan aguda discusión entre los partidarios y los críticos del proyecto de la Pradelle, que éste tuvo que abandonarse.

El asunto fué discutido nuevamente durante el mismo año, cuando Uruguay y Bolivia presentaron a las Naciones Unidas una resolución sobre el derecho de los estados para nacionalizar y explotar libremente sus riquezas naturales. Como recordarán, esta resolución, que no contenía inicialmente ninguna referencia a la compensación, dió lugar a un importante debate. Tal vez lo más importante de la discusión fué motivado por la propuesta de los Estados Unidos sobre modificaciones que establecían la regla de justa compensación en la resolución, y de manera clara y explícita. Aún cuando esta propuesta se abandonó y que la resolución tal como se adoptó fué algo que no nos preocupamos de apoyar, las Naciones Unidas dieron lugar a un debate sobre la cuestión de principio y se hizo un completo estudio del inde. seable asunto de la compensación parcial.

No me atrevería a afirmar si esto fué o no el punto culminante del debate. Sin embargo, es importante anotar que, desde entonces, se ha producido una fuerte corriente favorable a la regla clásica de la justa compensación. Esto ha sucedido tanto en los círculos gubernamentales como entre los abogados internacionales. En el último caso, basta únicamente

(3) Friedman, Expropriation in International Law 206-370 (1953). 
comparar la forma cómo se trató el asunto en la Conferencia de Siena $Y$ cómo lo fué en la reunión de la Asociación de Derecho Internacional de Nueva York, en Setiembre último. En ésta se vió la adopción de una reso. lución propuesta por Lord Mac Nair, declarando que los principios del Derecho Internacional estableciendo la santidad de los actos del Estado y el respeto por los derechos adquiridos por los extranjeros requiere

el pago de una compensación total al extranjero... tal como lo determina un acuerdo entre el Estado y el extranjero 0 , en caso de desacuerdo, por una autoridad internacional competente o la jurisdicción respectiva (4).

Esta resolución fué aprobada por el voto de todas las delegaciones participantes, con excepción de las del bloque soviético y de Indonesia.

Este cambio en la opinión es desde luego apreciable. Indica, por fin. la iniciación de un reforzamiento de esta regla vital de protección a la propiedad. Es particularmente grato para los Estados Unidos, ya que como Gobierno hemos tratado de mantener y defender este principio, tanto ers asuntos específicos en los cuales fué discutido, como en el desarrollo de nuestra política económica extranjera en su conjunto. $Y$, me es grato anotar que la gran mayoría de los abogados internacionales en este país han apoyado $y$ defendido estos esfuerzos.

Fué durante la controversia referente a las expropiaciones Mejicanas, como lo recordarán, que nuestro Gobierno hizo, lo que puede considerarse como la definición clásica de la regla clásica, cuando el Secretario de Estado Cordell Hull escribió:

El hecho de apoderarse de la propiedad sin compensación no constituye expropiación. Se trata de confiscación. No es menos confiscación por el hecho de existir una intención manifestada de pagar en alguna fecha en el futuro.

Si fuera permitido $\alpha$ un gobierno apoderarse de la propiedad Frivada de ciudadanos de otros países y pagat su valor cuando, a juicio de este gobierno, lo permita su extado económice y su propia legislación, las garantías que la constitución de la mayoría de los países y la ley internacional han previsto serían ilusorias. Los gobiernos no se hallarian libres de apoderarse de la propiedad más allá de sus posibilidades - deseo de pagar, y entonces los propietarios se hallarían desprovistos de todo recurso. No podemos discutir el derecho de un gobierno extranjero de tratar $\alpha$ sus propios nacionales de esta manera si así lo desea. Esto es asunto de política interna. Pero no podemos admitir que un Gobierno extranjero pueda apoderarse de la propiedad de los ciudadanos Americanos sin tomar en cuenta la regla de la

(4) 1958 Proceedings, International Law Association. 
compensación establecida por la ley internacional. Y tampo. co podemos admitir que ningún Gobierno, en forma unilateral y mediante su legislación municipal, pueda, como sucede en el presente caso, anular este principio universalmente aceptado por la ley internacional, que está basado en la razón, la equidad y la justicia (5).

Estos principios son también válidos hoy día. Son y continuarán siendo el punto nuclear de nuestros esfuerzos para proteger la propiedad de nuestros ciudadanos en el extranjero. De hecho, han sido reafirmados en términos igualmente enérgicos en la última década. En la controversia con Guatemala sobre expropiación de las propiedades agrícolas de la "United Fruit Company", por ejempio, nuestra adhesión a estos principios se expresó en los siguientes términos:

Cuando los Estados, en el ejercicio de sus prerrogativas soberonas, resuelven, como asunto de política, nacionalizar la propiedad de Estados extranjeros o de sus nacionales, se hallan en la obligación de pagar una justa compensación por tal propiedad.

Más lejos, refiriéndose a la naturaleza de tal compensación:

Se puede definir la justa compensación como la compensación que es "pronta", es "adecuada" y es "efectiva"; de otra manera el pago no es "justo" (6).

En asuntos de política general, tanto como en casos específicos de expropiación, nuestro Gobierno se ha preocupado de recordar estos principios. En el desarrollo del programa de tratados de la post-guerra ha seguido la práctica de negociar tratados o acuerdos a largo plazo sobre la protección de la propiedad que comprenden la regla clásica de la justa compensación.

Después, ha tratado de codificar la regla de manera a darle un reconocimiento explícito en un marco más apropiado, específicamente en tratados de amistad, comercio y navegación, esto es, en tratados destinados a promover inversiones en el extranjero y a protegerlas contra un trato desfavorable. Una cláusula típica está contenida en el $\mathrm{N}^{\circ} 3$, del artículo VI del Tratado con el Japón, de fecha 2 de Abril de 1953:

Ia propiedad de los nacionales y compañías de cualquiera de las Partes no podrá ser expropiada en los territorios de la otra salvo con fines de utilidad pública, y esto no podrá hacerse sin una justa y pronta compensación.

(5) 3 Hackworth, Digest of International Law 656 (1942).

(6) 29 Department of State Bulletin 357 (1953). 
Esta compensación deberá hacerse en forma efectiva y de_ berá representar el equivalente total del valor de la propiedad mencionada; y una reserva adecuada deberá haber sido hecha antes o al mismo tiempo en que se resuelva proceder a esa expropiación para determinar el pago consiguiente.

Dieciseis tratados más, negociados por los Estados Unidos, contieren memejantes seguridades inequívocas para las inversiones americanas que están protegidas de esta manera contra los tratos discriminatorios, adoptándose precauciones seguras para lograr, justas compensaciones en caso de expropiación. Hacemos toda clase de esfuerzos para sumentar el número de tales seguridades, y las negociaciones se hallan en buen camino con varios países.

No solamente el Senado ha aprobado este tipo de Tratados, sino que el Congreso en su conjunto ha dado su apoyo completo a la negociación de tales tratados, introduciendo una modificación en el "Mutual Security Act", de 1954, disponiendo que el Presidente deberá

intensificar un programa para negociar tratados de comercio.... que deberán contener disposiciones que tengan por fin alentar y facilitar la expansión de inversiones privadas en las naciones que participan en los programas que se realizan bajo el presente "Acto".

Además de estos Tratados, los Estados Unidos han pactado otros acuerdos bilaterales según los cuales los inversionistas americanos son indemnizados con respecto a ciertos riesgos políticos que provienen de las inversiones extranjeras. Es así cómo, actualmente, lás inversiones extranjeras pueden ser objeto de garantías gubernamentales contra tales riesgos como la expropiación o la confiscación por un gobierno extranjero. Este típo de garantía para las inversiones extranjeras funciona según las disposiciones de la sección 413 (b)(4) del "Mutual Security Act" de 1954, modificado en este aspecto.

Estimo que estos programas y esta política han logrado mucho para dar fuerza a esta regla de derecho. Y como lo hemos visto, este procedimiento ha conseguido crear un ambiente forvorable que aumenta tanto en este país como en otros países durante los últimos años. Como también lo hemos visto, esta regla, desgraciadamente, no ha logrado una aceptación universal. Existen aún opiniones gubernamentales y académicas que se inclinan a abandonar la regla de la compensación adecuada, pronta $y$ efectiva, en casos que se atribuyen a una modificación total de la estructura económica del Estado.

Es en esta atmósfera de parcial aceptación que se han planteado, en los últimos meses, algunas propuestas para concretar medidas unilaterales con el fin de proteger las inversiones extranjeras. Estos variados proyectos expresan de manera indudable cómo debe ser protegida la propiedad. Son ingeniosos, $y$, con un mayor estudio, tal vez podrían corregirse sus deficiencias. Sea como fuere, hacen ver claramente que existe una general preocupación 
en cuanto se refiere al deterioro de la clásica regla y a la imperiosa necesidad de volver a la regla de derecho.

Hasta el presente, los esfuerzos para lograr acuerdos multilaterales para alcanzar una regla conveniente han demostrado ser ineficaces. Es razonable inaicar que la diferencia en los sistemas lega'es, la variación de las políticas nacionales $y$ divergencias en los intereses económicos, han creado, en cada caso, obstáculos difíciles para el establecimiento de principios uniformes que puedan aplicarse a cada uno de los numerosos países interesados.

No deseo sugerir que una convención multilateral no sería deseable. En presencia de la evidencia, debo, sin embargo, declarar que, en la actualidad, veo pocas probabilidades para lograrlo. Considero que debemos continuar luchando para obtener una aceptación universal de la regla y que, por el momento, estamos realizando lo que nos corresponde mediante acuerdos bilaterales del tipo que he mencionado.

Queda la cuestión de saber cuanto más se puede hacer, y, específicamente, cuanto más se puede hacer para reforzar la fuerza e influencia de la regla clásica de la justa compensación. Creo que en este punto hay una importante labor para el Abogado Internacional Americano y sus colegas exiranjeros. Su papel es claro. Consiste en frustrar todo ataque de quienes pretendan comprometer este principio fundamental del Derecho. Digo esto deliberadamente, ya que la compensación parcial atenta al principio mismo.

Sin embargo, hay ataques indirectos, como directos, a este principio. Existe el fenómeno de la "confiscación disfrazada". Existen igualmente otras técnicas especiales. Por ejemplo, la compensación que no constituye compensación alguna, sino solamente promesas en el papel; bonos a largo plazo, cuentas bloqueadas, $u$ otras formas de dudoso o discutible valor. $Y$, tal vez más dañosa aún es la argucia que menciona todo menos el título verdadero. La injusticia de estas medidas es bastante grave cuando ocurren alteraciones fundamentales de la estructura económica o social. Esta injusticia es palpable cuando las medidas están inspiradas solamente por móviles polfticos, cuando, parc citar un ejemplo corriente, la propiedad privada es secuestrada como parie de una campaña para forzar la solución de un litigio sobre un territorio disputado. Aquí, también, el papel del abogado internacional es claTo. Debe oponerse resueltamente a todos estos ataques.

Al proceder así, prestará un gran servicio a la regla del derecho, haciendo resaliar a!go que muchas veces es ignorado: la sólida base de la clásica regla por consideraciones de razón, equidad y justicia. Le prestará, de la misma manera, un gran servicio insistiendo sobre las consecuencias que resultarán de un atentado a esta regla. Tal consecuencia fue señalada, de manera tajante, en el reclamo presentado por los Estados Unidos a Guaremala, con relación a la expropiación de la "United Fruit Company".

La obligación impuesta a un estado por la ley internacional de pagar justa o conveniente compensación al expropiarse la propiedad de extranjeros no puede ser derogada, desde el punto de vista internacional, por la legislación local. Si el contrario fuese cierto, los estados que traten de evitar el pago de la propiedad expropiada de los extranjeros podrian 
eludir toda responsabilidad pecuniaria por el simple hecho de modificar su ley interna. Toda obligación internacional podría, de esta manera, borrarse de las cuentas. Pero la ley internacional no puede burlarse de esta manera. El hecho de ser Miembro de la familia de las naciones impone obligaciones internacionales. (7).

Otra consecuencia tiene implicaciones no solamente para la regla del derecho sinó tambjén para el bienestar material de la comunidad mundial. Esto ha sido mejor expresado por uno de los miembros fundadores de esta Asociación, Chandler P. Anderson, quien, hace más de treinta años, señaló que el principio que salvaguarda la propiedad de los extranjeros de la confiscación

se ha convertido en parte de la ley de las naciones, no solamente porque representa un caso de justicia universalmente reconocido, sinó también porque es absolutamente esencial para el bienestar de toda nación, ya que si no fuera protegida, ninguna transacción comercial o financiera internacional podría llevarse a cabo. (8).

Esta opinión sigue siendo verdadera, y todos los países, cualquiera que sea su estado de desarrollo, harían bien en recordarlo.

(7) 29 Department of State Bulletin 357 (1953).

(8) Anderson, "Bases of the Law against Confiscaling Foreign-owned Property", 21 A.J.I.L. 526 (1927). 